\title{
Explaining the process of choosing clinical specialties in general medical graduates: A grounded theory
}

\author{
Shahram Yazdani ${ }^{1}$, Salimeh Khalili Azandehi' ${ }^{2}$ Aliasghar Ghorbani ${ }^{3}$, Sareh Shakerian ${ }^{4}$
}

\begin{abstract}
Objective: Internationally, the distribution of specialized physicians is a growing concern. The choice of medical specialties is a central issue in attempts to change this problematic situation. The current study aimed to explain the process of choosing clinical specialties in Iran's medical graduates.

Materials and Methods: The authors used grounded theory methodology. In 2016-2017, they conducted 14 in-depth, face-to-face, semi structured interviews with a purposive and theoretical sample of 10 medical graduates based on two criteria (those who intended to participate in the medical assistant exam and those who participated in the exam and their test scores had not yet been announced).

Results: After analysis of the interviews, 883 primary codes, 64 subcategories, 14 subclasses, and 4 main categories were obtained. The results of data collection and analysis at four levels by Strauss and Corbin (2008), which led to the theory and model in this field, showed the effectiveness of the process of choosing specialty results from the coordination between three dimensions of study, career, and favorable conditions imagined for the future life that takes place in a supportive environment with a developed welfare system and an inclusive academic culture.

Conclusion: With the help of the findings of such a study, the process and the main elements involved in this process can be determined and the causal relationships and mechanisms can be identified and intervened, which in turn leads to choosing medical specialty in line with the national priorities.
\end{abstract}

Keywords: specialty choice, clinical specialties, specialized physician, general physician graduates, grounded theory

\section{INTRODUCTION}

The choice of a medical specialty has implications for both students and the healthcare system (1). Given the population growth and new health-related needs, health systems around the world face the challenge of meeting these needs. Sometimes new diseases emerge and change the pattern of the existing diseases. This scenario deteriorates by limited number of medical staff and non-uniform distribution in specialized departments and geographic areas $(2,3)$, the choice of medical specialties is a central issue in attempts to change this problematic situation (1). Globally, the distribution of physician specialization has attracted more attention to the fact that the outcome of these choices may not meet the community needs $(3,4)$.

So identifying the reasons and factors that underlie the choice of specialties may provide a better understanding of students' preferences for a given specialty and may aid the development of intervention strategies (i.e., informational programs and extracurricular activities) according to the necessities of healthcare systems (1).

In Asian countries, medical students usually choose hospital-based clinical specialties and want to work in big cities. The migration of physicians from Asian countries to developed countries due to low salary structure, poor quality of education, and working environments in their country is another concern $(5,6)$.

Medical education in Iraq has been steadily declining over the past decades, because of previous wars, lack of resources, administrative corruption, poor governance, socio-economic and political instability, departure of teaching

\footnotetext{
1 MD, Ph.D. Professor, School of Medical Education, Shahid Beheshti University of Medical Sciences, Tehran, Iran.

2 Ph.D. Candidate of Medical Education, School of Medical Education, Shahid Beheshti University of Medical Sciences, Tehran, Iran.

3 Ph.D. Candidate of Medical Education, School of Medicine, Iran University of Medical Sciences, Tehran, Iran.

${ }^{4}$ Community medicine specialist, School of Medical Education, Shahid Beheshti University of Medical Sciences, Tehran, Iran.
}

Correspondence: Salimeh Khalili Azandehi

Ph.D. Candidate of medical education, School of Medical Education, Shahid Beheshti University of Medical Sciences, Tehran, Iran.

E-mail:b_khalili85@yahoo.com

Received: 20 Feb 2018, Accepted: 16 May 2018

(C) 2018 by the authors; licensee Modestum Ltd., UK. This article is an open access article distributed under the terms and conditions of the Creative Commons Attribution License (http://creativecommons.org/licenses/by/4.0/). 
personnel, and ongoing violence. In Iraq, personal interests and higher incomes were the most influential factors on the specialty priorities (7). The United Arab Emirates is worried about the management of the health sector by its national physicians, and despite the introduction of new policies in some specialties, such as gynecology, obstetrics, and pediatrics, there is still a shortage of national physicians. In this country, social and economic motivations are critical determinants of the specialty choice (8).

In Turkey, the financial factors and prestige were the driving factors for choosing a specialty (9). And Pakistan's health services have high levels of competition in high-income medical careers, such as cardiovascular specialty, and different levels of opportunities are offered for different specialties (10).

In Iran, GPs are forced to take entrance examinations to continue their education and choose their specialties based on their exam scores.

Since there is a significant competition for luxury, high-income specialties, and rest/low stress, some specialties that have high priority for health education and health systems are accepted less and have fewer applicants. This discrepancy between the priorities of the health system and demand of GPs and the student recruitment system leads to lack of application and vacancy of some specialties with high priorities.

According to National Institute for Testing and Assessment in Medical Education, in the academic year 2016-2017, the $43^{\text {rd }}$ medical assistant examination had 11,983 participants, competing for 3,153 admissions for 27 medical specialties in 42 medical universities. The distribution of the selected specialties by the first 100 ranks showed that only 7 of the 27 specialties were welcomed by them and $88 \%$ of them chose radiology, ophthalmology, and dermatology, and other specialties were not welcomed, while the competition was for the same specialties in the past year (11).

Despite the significant improvements over the past years in medical education and the growth of specialist workforce, the health system in Iran has several chronic problems, such as inefficient infrastructure, urbanization, changes in life style, prevalence of non-transmissible diseases and HIV, increased number of senior citizens, and absence of any master plan (12).

The policymakers of medical education and health are involved with many issues regarding the supply of a sufficient number of physician workforce (13). In this regard, in the first decade after the Islamic Revolution in Iran, two major reforms occurred in the health system. The establishment of primary health care (PHC) and the integration of medical education with the former Ministry of Health for the establishment of the Ministry of Health and Medical Education (MOHME) in 1985 initiated great progress in education of new specialty programs. But despite these brilliant advances over the past decades, and the recent Health Sector Evolution Plan (HSEP) in 2014, in recent years, with the changing community health needs, the health system does not have the necessary flexibility to meet the emerging needs of the population $(12,14)$.

In addition, Lack of a robust referral system, low medical tariff, non-significant difference between the service cost of a GP and a specialist, the facilitator role of insurance companies, and frequent medical visits because of lack of patients' confidence to physicians led to preference of referral of patients to specialists. As a result, the demand for specialized health care increases (15). All these issues caused the health system in Iran to face a significant challenge with regard to the number of prioritized specialties and their distribution to meet the community needs.

In literature review, it is clear that the works done for selection and distribution of clinical specialties are very limited in the world $(10,16,17)$ and existing models are also designed according to the context, and conditions of the society.

Selection of a specialty is a complex process and conducting qualitative studies seem necessary, especially by grounded theory, revealing the relationships and causations between various components of the concept, allows the researcher to devise a new theory in cases, where it is not possible to formulate a hypothesis (18), instead of using predefined theories.

Therefore, according to the challenges in promotion of health services in terms of need, number, and distribution of different specialties in the country, as well as the research paradigm, the nature, and native norms inside the country, we aimed to explain the process of choosing clinical specialties by GP graduates and generate substantive theory for facilitating design of specialty choice in the higher education system, so that, based on the findings of such a study, the process and the main elements involved in the process, the communications, and the causal mechanisms be identified and intervened, which will in turn lead to choosing specialty in line with the national priorities.

\section{MATERIALS AND METHODS}

Due to the fact that the process of choosing a specialty is a complex, challenging, and multidimensional process, people with different motivations enter this process and the study subject is completely interactive, it is necessary to 
Table 1: Participants demographics

\begin{tabular}{|c|c|c|c|}
\hline Participant NO. & Sex & Age & Occupation \\
\hline \multicolumn{4}{|c|}{ P1-5 (Who intented to participate in medical assistant exam) } \\
\hline P1 & Male & 26 & \multirow{5}{*}{ General Practitioner. Graduate } \\
\hline P2 & Famale & 25 & \\
\hline P3 & Male & 27 & \\
\hline $\mathrm{P} 4$ & Famale & 26 & \\
\hline P5 & Famale & 25 & \\
\hline \multicolumn{4}{|c|}{ P6-10 (Who participated in the exam and their test scores have not yet been announced) } \\
\hline P6 & Famale & 26 & \multirow{5}{*}{ General Practitioner. Graduate } \\
\hline $\mathrm{P} 7$ & Male & 28 & \\
\hline P8 & Famale & 25 & \\
\hline P9 & Famale & 27 & \\
\hline P10 & Male & 29 & \\
\hline
\end{tabular}

analyze this complex and comprehensive process by a qualitative methodology, report the details from the informants, and conduct the study in a natural environment. Given that the goal of the theory is identification, description, and explanation of interactive processes between individuals and groups that occur in a social context (19), this qualitative research was carried out by grounded theory, in order to study the process of choosing a specialty, obtained directly from decision makers in this field by open ended method.

\section{The Grounded Theory Approach}

In this study, considering that the researchers are ontologically committed to realism, and believe that truths and knowledge exist beyond the minds of individuals, and that individuals are trying to recognize and discover the facts, practically, the Charmaz's approach was rejected. Because this school believe in making the truths in the minds of individuals, so with this view, there are as many theories as the number of individuals for a specific phenomenon and this view is not consistent with the researchers' view.

Regarding epistemology in this study, the researchers believe that the emptiness of the researcher's mind and the mere reliance on the data obtained cannot attest that all aspects of the specific phenomenon are concerned. That is, previous studies of researchers and extensive literature reviews guide data collection, analysis, and the results toward collection and analysis of the maximum and most relevant data and providing the results based on the existing context.

Also, the interaction of researchers and participants is very important for making sense of data. Based on Strauss and Corbin (2008), an increasing emphasis has been placed on the participation of researchers and participants in making sense of data. Therefore, with this approach, epistemologically, researchers believe in subjectivism that is closer to Strauss's approach. Therefore, the grounded theory approach in this study was based on the Strauss and Corbin method and ultimately the philosophical position of the researchers was epistemological realism.

\section{Participants and Sample Size}

The study population was general physician graduates. Sampling was based on two criteria (those who intended to participate in the medical assistant exam and those who participated in the exam and their test scores have not yet been announced), who were selected from the study population, first purposively, and then theoretically.

During sampling, after choosing the individuals, they were contacted by telephone calls, the objectives and the subject of the study were explained for them, and they were invited to participate in the study and after obtaining informed consent, while ensuring that they can leave the study at any time and all data is collected unanimously (the names will be replaced by special numbers or codes), the interview was conducted in three phases.

Given the fact that after the first study, we achieved a general framework for the interview procedures (to be publishing), it was decided to conduct a pilot interview with two of the participants, and after analyzing each interview, the need for new questions or modification and completion of the questions, as well as the next participant be determined for the interviews. The second phase, with a theoretical sampling, consisted of six exploratory interviews and after analysis, the researchers concluded that the data were relatively saturated, and in the third phase, to confirm the data, two other participants were interviewed, and by analyzing the new data, the codes and categories obtained from previous interviews were approved and it was confirmed that the data was saturated and no new information was obtained. A total of 14 interviews were conducted with 10 interviewees. Some interviewees were interviewed twice to answer the questions raised after the first interview in the mind of the researcher (Table 1). 


\section{The Study Setting}

The setting of our study included the health system of the country, consisting of medical science universities and the health services system.

\section{Data Collection}

The main method of data collection was extensive, semi-structured, and interactive in-depth interviews. All interviews were conducted and recorded by one researcher and immediately written down on paper thoroughly. The interviews were conducted in a quiet environment at a time and place appropriate for the participants, and the mean duration of the interviews was between 40 and 50 minutes. The main criterion of the researcher for the number of interviews was the use of key informants, data, categories, emerging theory, and theoretical saturation. Memo writings (case-based memos and conceptual memos) were very helpful in data collection, i.e. during or after the interview, and in analysis. Memos are deep thoughts about events, written usually after leaving the scene or during data analysis (19). Writing a memo in grounded theory is essential for the development of theory (20).

\section{DATA ANALYSIS}

To analyze data and to identify data that observed the context, process, and outcome, analytical tools such as asking questions from data, (constant and theoretical) comparison, theoretical analysis, flip-flop techniques, raising red flag, different meanings of one word, attention to body language and emotions expressed, writing memos and story line were used (19).

Digital files were implemented. Grounded theory was used to determine and coding the factors influencing the choice of specialty. The codes were organized into meaningful and logical categories, and the main categories were identified by establishing an association between categories. The analysis was performed using the Atlas Ti7 software, by Strauss and Corbin method (2008) at four levels of data analysis for concepts, data analysis for the field, insertion of the process into data analysis, and analysis for composition of categories and theoretic integration.

\section{Assessment of Scientific Validity of Data and the Study Quality}

In this study, the relevance of the results was reviewed and shared by some of the general physician graduates, who were considered as target group. During the interview, findings, process, story line, structure, and the final model of the study were shared and discussed with three experts, who were directly involved in the process of choosing medical specialty at the country level and were not among participants. In addition, the findings were sent in the form of a storyline to two of the study reviewers, who were aware of the subject.

In this study, one of the researchers, as expert, continuously and thoroughly examined and controlled the steps and details of the work in order to clarify certain concepts, including the concepts of choosing a medical specialty and field.

It was tried to completely explain the reader how and in what background, the process of choosing clinical specialties takes place and what the constraints and facilitators are. It was attempted to address what was needed to narrate the story of choosing clinical specialties in Iran and could have given it a more detailed interpretation.

Researchers were involved with data in a rather long time and worked with them (for approximately one year) and spent enough time to collect data, interviews, and observations, through meetings and in different times. In expressing the findings and ideas, the researchers tried not to confuse the readers by expressing the methodological decisions clearly. The researchers studied deeply and dealt with details of how to choose clinical specialties and removed them from the superficial level and deepened them. Also, in order to deepen the results, the research team tried to extract multiple citations in the results section from the common language of the studied population and provide a clear picture of the process of choosing clinical specialties.

To achieve maximum sensitivity in the analysis process, the research team wrote the personal experiences and assumptions to prevent pre-formed bias or mention them in memos. In addition, before the study began, no extensive literature review was performed, which made the emerging to be more probably derived from the study data.

\section{RESULTS}

In this study, generally 10 general physician graduates were interviewed in person. After analysis of the interviews, 883 primary codes, 64 subcategories and 14 subclasses and 4 main categories were obtained (the expected utility of study, the expected utility of career, the expected utility in the future life and environment, and previous life experience). 
Table 2: Subclasses and subcategories of the main category "environment and experience of past life"

\begin{tabular}{|c|c|c|}
\hline Subclasses & Subcategories & Main category \\
\hline Influence of family in specialty choice & \multirow{4}{*}{$\begin{array}{c}\text { Family conditions, preferences and } \\
\text { experiences }\end{array}$} & \multirow{9}{*}{$\begin{array}{l}\text { Environment and } \\
\text { previous life experience }\end{array}$} \\
\hline The role of friends and peers & & \\
\hline The impact of past experiences \& events & & \\
\hline The importance of encouraging $\&$ experiences of others & & \\
\hline The experience of clerkship \& internship & \multirow{4}{*}{$\begin{array}{c}\text { Conditions, exposures and experiences } \\
\text { as a medical student }\end{array}$} & \\
\hline Faculties' characteristics in GP & & \\
\hline Residents' experiences & & \\
\hline Self-directed choice & & \\
\hline Socio economic background & Wider social and economic environment & \\
\hline
\end{tabular}

\section{Expected Utility}

In the grounded theory, the central category is the core of the research and may be selected from other categories or by repeated study of existing categories and attaining a higher level of abstraction. In order to reach the central category, all categories must be integrated and the role of each should be clearly identified in the process and structure of the data analysis (19).

In this study, most participants were concerned about the concepts of achieving prosperity, satisfaction, comfort, peace, happiness, and balance, as a goal in life, all of which directly or indirectly address the concept of the expected utility, and ultimately the high emphasis of the participants resulted in the specific category and its centrality, the impact on other categories, the direct connection with all the obtained propositions and that it confined sufficient level of abstraction made it as the main goal of choosing specialty in Iran.

"I look for peace, comfortable conscience, relative welfare, a good social status, and a balance between my occupational, social, and family life, and I think I can get to this with this choice, be for myself sometimes, and be satisfied, reach a decent level of peace that requires prosperity, no concern or stress, and good endings for everything. (P7)

\section{The Data Analysis for the Concepts}

This analysis is, in fact, the open coding that generates basic concepts and categories. The coding varies in terms of details from micro- to macro-type. Microanalysis is often used at the beginning of the research, when the analyst tries to enter the data and seeks to extract all possible meanings from the data, but the macro analysis goes backwards and searches for data from a wider perspective. Micro and macro analysis are used together in data analysis (19), as the researchers consider all the possible findings and meanings in the data, and label the data with a conceptual label. To construct the mentioned concepts, the data was segregated into manageable parts. The concepts were named by the researcher or derived from the words of the interviewees. These labels were not fixed and could be modified.

\section{The Data Analysis for the Field}

During open and axial coding, field analysis of the data was also carried out and it was necessary for the researchers to ask questions about "What conditions would lead to choosing clinical specialties by GP graduates? What are the barriers and facilitating circumstances? Who are involved in this? What are the consequences of this choice?" For example, researchers in field analysis looked for conditions that would somehow affect the formation of the expected utility as a central phenomenon and facilitate it. Also factors that are a barrier to the formation of the expected utility were considered. In this context, it seems that the main category of the "environment and previous life experience" is a factor that can create the expected utility at the individual level.

The environment and previous life experience. The environment and previous life experiences are the key factors in what happens in the future life, achieving all goals and needs, and ultimately achieving the ultimate goal in life, i.e. happiness and satisfaction (Table 2).

Family conditions, priorities, and experiences. The effect of encouragement, support, consent, coherence, insistence, coercion, counseling, and experiences transmitted by family members, along with the individual's personal interests in family and respecting them and their views, along with the individual's sense of commitment to reimburse the efforts of the family play a crucial role in individual's decision making.

"By the choice of specialty, my father encouraged me to study dermatology, because my dad was a general surgeon and was aware of the conditions and career market, and wanted me not to get involved with work as much as him." (P8) 
Sometimes the impact of friends and peers is stronger than family. "My friends always said that internal medicine fits my feelings, but one of my best friends told me that you should study further and not suffice to internal medicine. It was very motivating for me and energized me..." (P10)

Conditions, exposures, and experiences as a medical student. By drawing the behavior and occupational discipline of various specialties, by the participants, derived from the experiences gained from internship and contact with professors and other residents, an environment full of insults, intimidation, and conflict in the surgical specialties in one hand and a relaxing environment in the para-clinical and ophthalmology specialties on the other hand, made the academic atmosphere of the medical education system unbalanced and non-standard.

"In internship I saw that a first-year resident may be up more than 80 hours in the hospital without a rest or an orthopedic resident who was in the hospital for one month and was not allowed to go home or, at least, have a room to rest. So, I do not want such quality of life; being a surgeon, and, such state of excitement and doing fabulous things did not satisfy me. I would prefer to spend my day calmly and have some time to do the rest of my work and ..." (P5)

Based on evidence from data, the approach to focusing on prestige is formed due to convenience, low stress, and luxury of the specialty and high income during the period of GP education.

"In my opinion, two points are the most important things: the specialty's income and the low stress. This is formed in minds and most wish to achieve, right or wrong, and everyone wants to enter these specialties." (P6)

Broader social and economic environments. The concept of each particular behavior is inferred from its cultural and social environment. According to information of data analysis, one of the main issues in choosing specialty in Iran is income because people want a high living standard, wealth, and welfare. Secondly, the growing gap between primary care specialties such as internal medicine and pediatrics with other specialties had a negative impact on the decision to enter primary care specialties or work in deprived areas. In addition, the financial weakness of the family and poor economic status in the community tend people toward high-income specialties.

"I learned that I can be very helpful by medicine. But, if I did not have a good income, I could not accomplish many of my works and decisions; in our society, where money talks, I told myself that I must have a career that can both provide me money and help people." (P10)

\section{Entering the Process to Data Analysis}

The next step in data analysis is identification of the strategies or processes that participants used in response to the field. Because in the present study, the data indicated changes in the behavior or reaction or individuals' feeling in an evolutionary process over time and change in underlying conditions, the process was described by continuous and interrelated steps and at each step, the individuals' reactions are more likely to respond to problems, needs, and conditions and the consequence of these reactions is, in turn, a background for subsequent actions of individuals. Accordingly, three main categories were identified: the expected utility of study, the expected utility of career and the expected utility in the future life.

The expected utility of study. Decision on studying a particular specialty requires correct information and charting the conditions during and after study and long-term goals in order to make more certain decisions and achieve expected utility at this level (Table 3). 
Table 3: Subclasses and subcategories of the main category "expected utility of study"

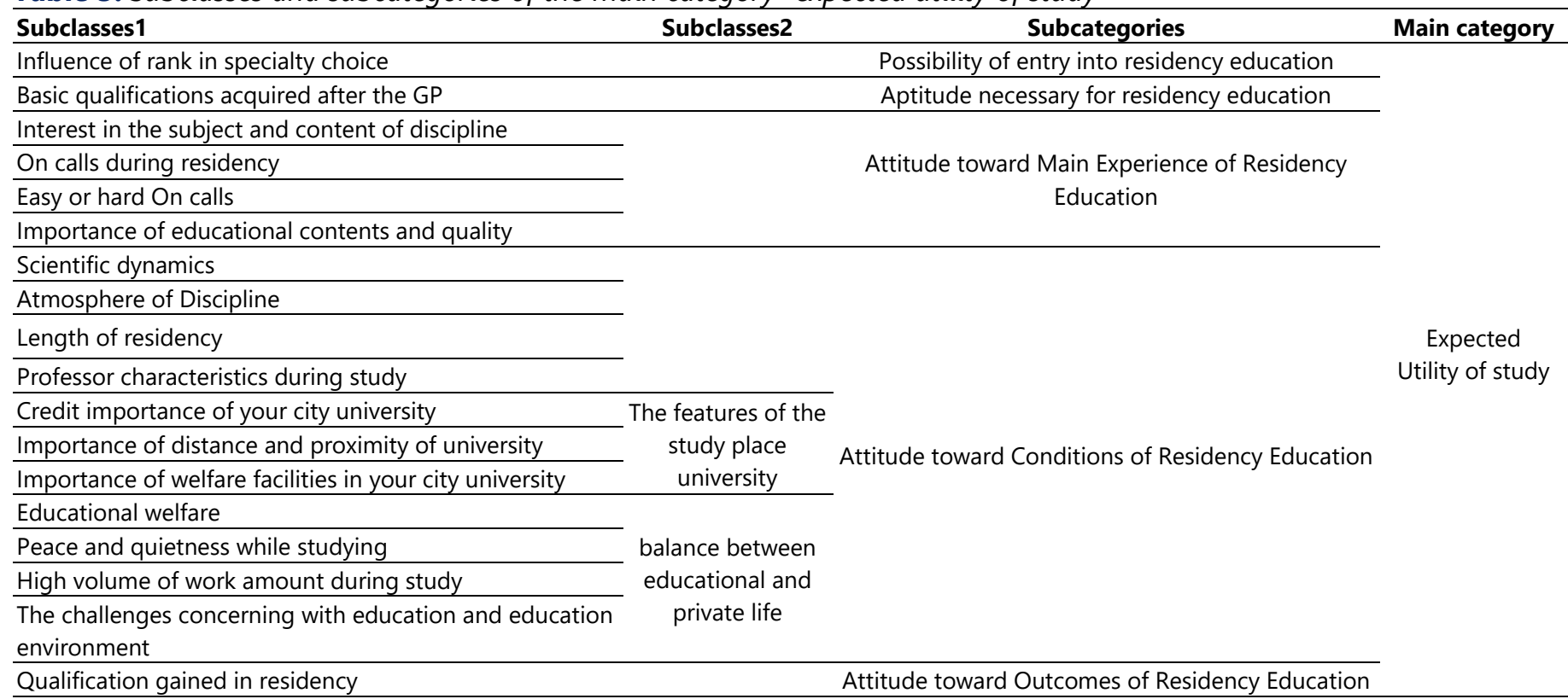

Possibility of entry into residency education. Participants explicitly acknowledged that educational decisions are mainly made based on the rank; this is so pivotal that it determines the range and spectrum of the individual's choices, and the high scores will give him/her a wider decision range.

"Anyone who ranked better would be accepted in a better specialty. I got a good score I had a wide choice. The range of scores indicates that they can select one specialty. I have never seen anyone reaching the $200^{\text {th }}$ rank who would not select dermatology and would study infectious diseases. The score's power is so high that you should not search for other things with the score you get." (P1)

Aptitude necessary for residency education. Talent is a sign of a person's ability to learn new skills and knowledge and associated with specific specialty choice.

"Depending on the type of specialty, you need to learn knowledge and skills. It is important how much you can handle stress, how much you can tolerate unpredictable circumstances, how much you can decide in difficult and urgent situations, and how much determined you are to enter this training." (P2)

Attitude toward the main experience of residency education. Practically, residential education is independently empirical, and takes place in the environment of health care, the kind of experiences that occur in this process are one of the factors that a person considers in preference to choose a particular specialty to achieve utility in study and as an ultimate goal in life. In this regard, interest in the subject and content of the course, the number of residency shifts, the lightness and intensity of the shifts, and the content and quality of education during the residency period are the concerns that make people's priorities for choosing specialty and achieving desirable conditions.

"I always see radiology residents are joyful and happy, because they do not have ill patients, or difficult shifts, and the number of shifts are limited. This is very important for me; these conditions are thriving, beside the financial conditions." (P5)

"Always neurology is a more attractive specialty for me, as it is more concerned with analytical issues, the cause of neurological diseases. But most diseases you have in this discipline do not get the right treatment, there are too much for them to do. Neurologic diseases still have many unanswered questions." (P2).

Attitudes toward conditions of residency education. The environment and conditions governing Medical Education System have a major impact on the priorities of choosing a specialty. From the point of view of the participants the scientific dynamicity of the specialty, the governing atmosphere, the length of the residency period, the characteristics of the professors during the residency, and achieving a balance between education and personal life are the characteristics of the specialty, affecting their choice, and determines the utility of studying in that specialty for each individual.

"I really liked surgery, but when I entered the hospital, I saw that it was completely different from what I had in my mind, not in terms of career, but in terms of the details of the career, that is, the whole atmosphere of surgical fields is 
Table 4: Subclasses and subcategories of the main category "expected utility of career"

\begin{tabular}{|c|c|c|c|}
\hline Subclasses 1 & Subclasses2 & Subcategories & $\begin{array}{c}\text { Main } \\
\text { category }\end{array}$ \\
\hline Conditions governing on specialty saturation and distribution & & Possibility of Entry into & \multirow{26}{*}{$\begin{array}{c}\text { Expected } \\
\text { Utility of } \\
\text { career }\end{array}$} \\
\hline Form of necessary qualification while graduation & & Specialty Practice & \\
\hline Psychomotor dexterity & & Aptitude Necessary for & \\
\hline Other professional talents and abilities & & Specialty Practice & \\
\hline interest in the nature of work & & \multirow{7}{*}{$\begin{array}{c}\text { Attitude toward Main } \\
\text { Experience Specialty Practice }\end{array}$} & \\
\hline Interest to continue working in academic positions & & & \\
\hline Consequences caused by treatment & & & \\
\hline Mental stress & & & \\
\hline sex & & & \\
\hline Length \& continuity of care & & & \\
\hline Specialty attraction and variety & & & \\
\hline Job setting preference & & \multirow{13}{*}{$\begin{array}{l}\text { Attitude toward Conditions of } \\
\text { Specialty Practice }\end{array}$} & \\
\hline Influence of Work hours in specialty choice & & & \\
\hline \multirow{4}{*}{ Psychological stress } & Frequency of error & & \\
\hline & Magnitude of side effects & & \\
\hline & Predictability of side effects & & \\
\hline & Controllability of side effects & & \\
\hline Initial capital requirement & & & \\
\hline Conditions of medical plan spending & & & \\
\hline Role clarity & & & \\
\hline Critical condition of patients & & & \\
\hline Office opening possibility & & & \\
\hline Cultural contrast and clashes & & & \\
\hline Exclusive specialties & & & \\
\hline Professional prestige & & \multirow{2}{*}{$\begin{array}{l}\text { Attitude toward outcomes of } \\
\text { Specialty Practice }\end{array}$} & \\
\hline Impact of income on specialty choice & & & \\
\hline
\end{tabular}

very bullying, too formal, the higher residents could do whatever they wanted, by the forest law, the stronger bullied the weaker, I cannot stand such cruelty and these things." (P4)

The role of the study_place_university and its characteristics in three areas of credit, distance and proximity, and facilities at the university are the dimensions of this preferred framework.

"Everyone chooses specialty based on the credit of the study place university. Well, preferably, I do not want to be far from my place of residence and my family. I choose the nearest university according to my conditions. It would be better, if I had a dormitory, but the residency income is also nothing." (P8)

Attitude toward outcomes of residency education. One of the functions of the residency education system is to achieve outcomes that are part of the concern of those studying in different specialties to achieve their expected utility in this regard.

"The most important consequence is that you find a license to practice in the specialty you studied and have the chance to be more specialized and reliable, to give specialized consult, to be a reference and, in fact, is the platform to launch for the career market." (P2)

Expected utility of career. Each person follows specific utility regarding professional and career fields of the specialty choices and expects to achieve the expected utility in the career and, ultimately, in future life by a choice as close as possible to their preferences (Table 4).

The possibility of entry into specialty practice. The number and distribution of specialists, at the moment, provides the possibility of choosing the location of the desired career or the possibility of productive employment for the individual.

"The truth is that internal medicine is a specialty that is not very popular recently, because it's time-consuming and has low income, yet there are too many internists; in other words, the market is not so good. To some extent, I will have trouble where I want to work, regarding employment in a hospital or getting a client for my office and hospital admissions." (P10)

Participants had their own convictions that if the formation of individual competencies during graduation to enter the career world does not occur in the person, the possibility of working in the desired profession encounters difficulty. 
"In some specialties, when a person graduates and enters the career market, he/she has the ability and competency to work, and only needs to compensate some deficiencies; but in some specialties like orthopedics and surgery are not the same, the person realizes during working that there are lots of things he/she does not know and has to learn." (P5)

Aptitude necessary for specialty practice. For many participants, paying attention to having Psychomotor dexterity and other skills and professional competencies, relative to the type of specialty is the necessary precondition for entry and success in the specialty.

"I think that a radiologist should have a good spatial visualization and should be able to work with the devices. It does not have much practical work. It's important to have patience to sit for a while and work seated. Some people do not want to sit permanently." (P5)

Attitude toward main experience of the specialty practice. The interviewees mentioned items like interest in the nature of work, interest in continuing to work in an academic position, the consequences of treatment, mental stress, gender, length and continuity of care, the attractiveness and diversity of the field, determined their priorities in specialty choice. The participants' expressions indicated their attitude toward specialties with the least mental stress that could suggest the current view of the Iranian society.

"The most important thing in my choice is having no stress, and my most important motivation is comfortable life. It means that I do not want to have stress every day in my life. I will go home after work and do not want my mind to be occupied. I do not want to have challenge every day. These worries me; not that I don't like visiting patients, but it gives me stress." (P5)

As the data shows, the current focus is on moving toward specialties with more manageable lifestyle, fewer working hours, and higher income.

"My personal interest is general surgery, but I will never go for it, because it is difficult for a woman; I personally cannot stand surgery and the psychosocial pressure. Because of this, as ophthalmology has fewer work for a woman, I prefer to study that." (P6)

Attitude toward conditions of the specialty practice. Today, with the development of specialties and medical subspecialties, knowing that a specialty really fits the person is difficult, until the person has the chance of completely immerse in that specialty. Therefore, having proper and accurate information about the occupational characteristics of each specialty helps the individual determine their priority of choice among different specialties and be able to reach the expected utility by a more appropriate choice.

In this regard, the individual's preferences toward occupational environment, working hours, predictability, the amount of emergency cases in that specialty, mental stress, and exclusiveness of that specialty are important considerations of the participants.

"Neurosurgery is a problematic specialty, has a lot of shifts; ill patients may arrive at night and midnight; you may not be able to rest for one hour and have to stay in the hospital for hours and spend a lot of time working." (P7)

"The responsibility is really high, because the eye is a vital organ for every human being; many residents suggested not to enter ophthalmology, because of the high stress of the surgeries, high responsibility and complaints against physicians, as well as unpredictable situations it may have."(P6)

"I think a number of specialties were more successful in keeping their credibility, like ophthalmology, because of the sensitivity of the career and the fact that not everyone can enter his field. These are important to me." (P4)

The amount of initial capital required to start a career and office and work in the relevant specialty, governing conditions for compulsory work, the clarity of the role and professional duties of the individuals, the degree of patients illness, the concern about the possibility of having an office, and cultural conflicts are other issues raised.

"With this much distribution of different specialties and their great quantity, there are surely challenges to consider, such as the issue of the possibility to gain reputation and position, and attract clients, and that you will be able to create a good working environment with the presence of professional competitors." (P7)

Attitude toward outcomes of specialty practice. The consequence and effectiveness is crucial in method of choosing, both for each individual to achieve the best level of utility, and for the health care system of the country. Based on data analysis, participants were looking for occupational prestige and income. The trend of choosing a specialty by GP graduates is toward low stress and high-income specialties.

"I think, ophthalmology is currently the top specialty and one of the top three. Ophthalmology, radiology, dermatology, and cardiology are, of course, one of the specialties that the first ranks usually welcome. There are two important things behind this: low stress and prestige. Most students wish to reach it and to enter these specialties." (P6) 
Table 5: Subclasses and subcategories of the main category "expected utility of life"

\begin{tabular}{|c|c|c|c|}
\hline Subclasses1 & Subclasses2 & Subcategories & Main category \\
\hline Achieve physiologic needs & & \multirow{6}{*}{$\begin{array}{c}\text { Balance between work } \\
\text { and private life }\end{array}$} & \multirow{6}{*}{$\begin{array}{l}\text { Expected } \\
\text { Utility of life }\end{array}$} \\
\hline Achieve safety and security needs & & & \\
\hline Achieve romantic needs and social engagement & & & \\
\hline Achieve needs of respect and dignity & & & \\
\hline Satisfy self-actualization needs in individual level & \multirow{2}{*}{$\begin{array}{l}\text { Achieve self-actualization } \\
\text { needs }\end{array}$} & & \\
\hline Satisfy self-actualization needs in social level & & & \\
\hline
\end{tabular}

Expected utility in the future life. All human beings are seeking to meet their needs at different levels. Concepts of well-being, comfort and pleasure, career, decent income, sense of security, attachment, love, interest, respect, social status, self-esteem, and interest in satisfying potential abilities are all the basic life needs of every individual that empower the individual's behavior. The behavior of individuals at certain moments is affected by the most severe need. Career and specialty choices also aim to satisfy these needs to reach ultimate balance and final utility in life.

"I am looking to reach the end of everything in my life, ultimate calmness, satisfaction, comfortable conscience, high income, and enjoying all the hours and moments of my life and think that I will achieve these goals by my choice" (P9) (Table 5).

\section{Analysis for the Composition of Categories and Theoretical Integration}

The final stage of the analysis was composition or integration of categories for formation of theory. Theoretical integration is one of the most difficult methods necessary to accomplish the grounded theory (21). The composition refers to the process of connecting the categories around a central category and refining and trimming the theoretical structure derived from it. To this end, after identifying the central category (expected utility), the coding paradigm, theorems, writing descriptive stories, revising the memos, the raw data, and writing the happening analytic story was used to ultimately achieve the theory.

\section{The Coding Paradigm}

To connect the structural factors to the process, Corbin and Strauss coding paradigm (2008) was used. This paradigm helps to link the structure to the process and identify it; the main components of the paradigm included: 1) the condition or structure resulting from answers to the questions of what? Why? Where? And how things have happened and help us determine the situations. 2) There are interactive/emotional reactions. Individual responses are rooted in situations, problems, incidents, and events. 3) There are consequences of interactive reactions or emotional responses to the event.

\section{The Concepts}

Concepts are the terms that represent groups or classes of objects, events, and actions that share some of the most important common features and classify the specific phenomenon, as building blocks of theories (18). Choosing a specialty, preferences, expected utility, environment and past life, expected utility of study, career, and the future life are the main concepts of the theory.

\section{The Theorems}

Theorems indicate the relationships between two or more concepts or variables. If concepts are as building blocks of theory, communicational sentences can be considered as chains that connect concepts (22). The main theorems of the theory extracted from the data are as follows:

1- In specialty choice process, GP graduates turn to a number of strategies to make the best choices in spite of the obstacles and limitations.

2- GP graduates pass different conditions and methods for obtaining information about different specialties and, finally, identifying their priorities to achieve the maximum expected utility.

3- If the strategies, experiences, conditions, and exposures that the person has gone through can guide him/her in the best way, the outcome of choosing the best specialty will be based on the individual's need and desire, achieving the expected utility in life, and meeting the needs of the individual and society.

4- The structural-contextual factors (past family experiences, circumstances, exposures and experiences of the individual as a medical student and wider social and economic environments) can have positive or negative effects on the selection process. 
5- The structural-contextual factors (due to lack of academic ethics, balance, standards, and maturity of the governing academic atmosphere on medical education systems, lack of professional codes and their implementation, and thus creation of a competition for high-income specialties and low stress due to lack of developed welfare systems along with financial imbalances and previous life deficiencies) will have negative impacts on the process of choosing specialty based on the community needs.

6- The structural-contextual factors (in case of application of professional codes, maturity of academic culture, existence of developed welfare systems, and creation of positive experiences in academic processes and career selection) can have positive impacts on the process of choosing specialty based the community to the number and distribution of specialists in different fields.

7- By modifying the health system and payment methods and ensuring the expected utility of people's lives, choices will move toward meeting the community needs.

\section{DISCUSSION}

The factors that underlie the choice of a medical specialty is largely unexplored in Iran. Interestingly, we found that in choosing a specialty, our past experiences are our insiders and the individual's selection priorities are determined through a process for attaining utility in the three components of study, career and future life and by meeting the needs of people at different levels and achieving balance in life, the ultimate and expected utility in life will be achieved.

We found that in study during the residency period, participants considered the ranks as the pivotal factor in choosing a specialty and criticized it as the only benchmark in choosing a specialty. The inappropriate, hierarchical, and unconventional governing atmosphere, and the non-standard environment in the educational system were considered as one of the reasons for not choosing many specialties, like surgery.

The absence of a correct payment system, attention to a number of specialties, convenience, working hours, and better balance between work and personal life were reasons that justified people's preference to some specialties, like radiology, ophthalmology, dermatology, and cardiology. These findings are compatible with the perspective that preferences for controllable lifestyle specialties are associated with interest in a stable and secure career, a good quality of life, and better control of the time spent during work $(23,24)$.

According to the interviewees, the ruling conditions of compulsory working, the distribution and saturation of specialties, the possibility of having an office, and the need for initial capital to start working were the concerns of specialists, which challenge the conditions of achieving the intended results.

Given the fact that individuals seek to meet their needs for a final balance in their lives, they try to move toward provision of the expected utility in life by choosing specialties with higher income, comfortable lifestyle, and shorter working hours, which is the process currently happening in choosing specialty in our country.

General practitioners believe that the medical education system ship does not target people to their goal and the disproportionate professional and academic atmosphere and the lack of proper exchange of knowledge and skills due to the high educational volume, high workload, inadequate welfare during study, occupational stresses in line with the socio-cultural environment, people are looking for the best choice with academic, occupational and lifestyle conditions that by providing maximum welfare, will lead them to the desired utility.

The present results suggest that some factors should be further explored to expand medical graduate's choices of needed medical specialties based on data which cannot be generalized to other countries. Therefore, certain strategic interventions may increase the choice of specialties that currently suffer from shortages of professionals in Iran. We propose the expansion of opportunities during internships, empowerment of role models, Balance of the governing academic atmosphere, developing welfare systems and financial incentives that can be used to increase the preference for some specialties in Iran, which has also been suggested elsewhere $(1,25,26)$

\section{The Model for Utility of Specialty Choice in GP Graduates in Iran}

The results of data collection and analysis at four levels of data analysis for concepts, data analysis for the field, insertion of the process for data analysis, and analysis for composition of categories and theoretical integration by grounded theory resulted in "utility model for choosing a specialty in general medicine graduates in Iran" as shown in Figure 1. The central category in this study was considered as the expected utility. 


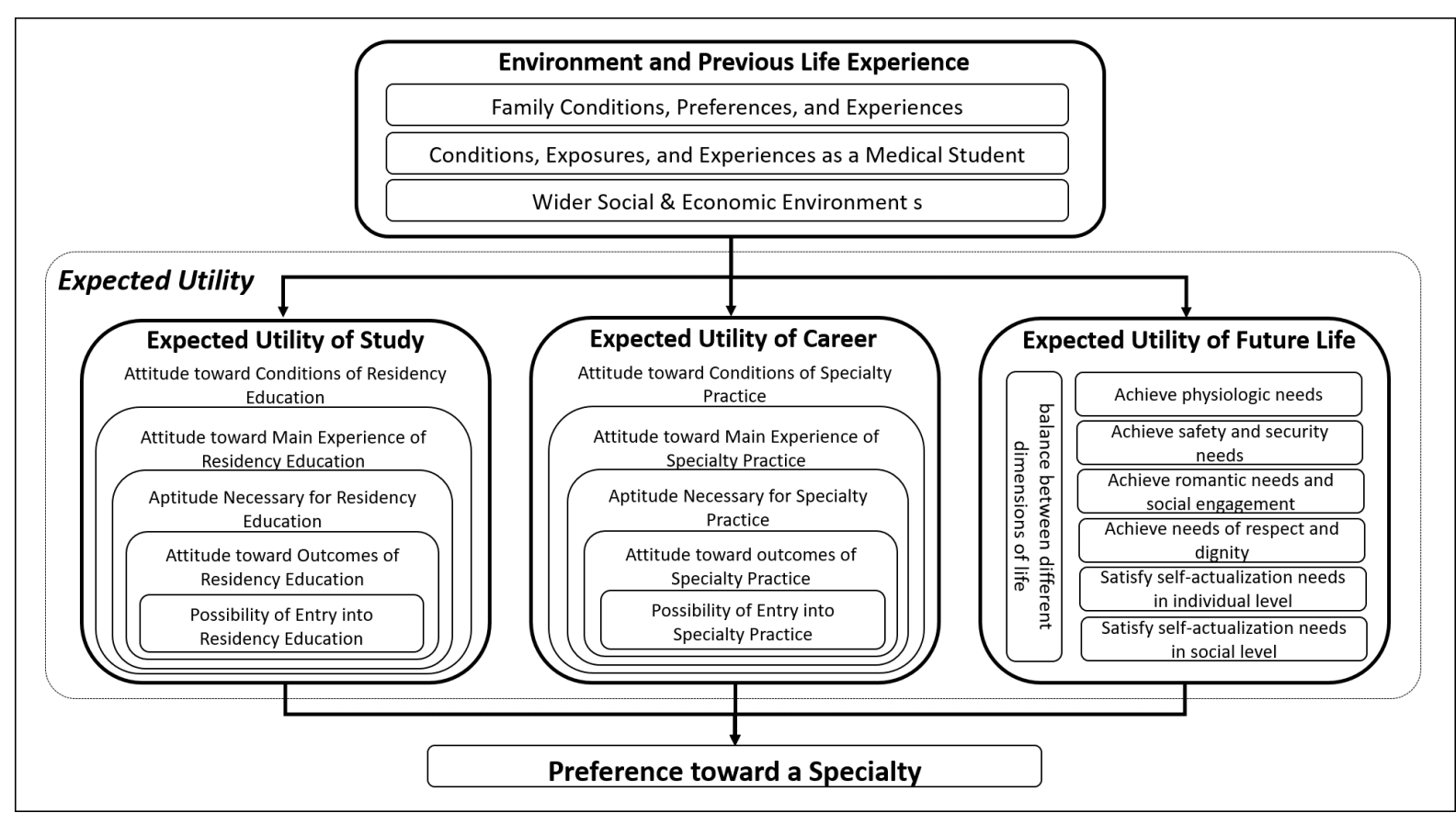

Figure 1: The final model of utility of the specialty choice in medical graduates in Iran (SCL model of choice)

Table 6: Experts Demographics

\begin{tabular}{llcc}
\hline Role & Sex & Grade & Experience, y. \\
\hline Deputy General Specialist Medical Council & Male & Specialist & 18 \\
\hline Secretary of the Assistant Education Council & Male & Ph.D. & 20 \\
\hline Head of National Institute for Testing and Assessment in Medical Education & Male & Ph.D. & 16 \\
\hline
\end{tabular}

A closer look in the resulting model shows the following noteworthy points:

In the process of choosing a specialty, the condition for achieving the desired utility is to prioritize choosing a particular specialty. The expected utility flows in all stages of the process of choosing a specialty, and given that the goal of all people is to achieve this level of utility in life, this utility should be clearly seen in all components and elements.

In the resulting model, the factors and requirements for achieving the expected utility are explained at three levels; at the first level is the educational system. It is quite clear that people have to take a course in choosing a specialty as a career, and the educational system should play its role in responding well to achieving the expected utility in future life. At the second level is the profession or career; at this level, the graduate enters the professional work environment and if moving towards the process of choosing a specialty and achieving the desired utility, it is necessary to assess the conditions and characteristics of the career and make a decision based on that. And at the third level is the future life, which is in the direct connection with the selection of the preferred specialty, and achieving the desired utility in life. At this level, people are trying to satisfy their basic needs in a hierarchical manner in order to achieve balance in different aspects of life, so that they can achieve the ultimate utility in life by choosing correctly.

\section{The Approval of the Model by Experts}

After completing the study and presenting the model, the story line, structure, and the final model of the study was shared and discussed with three experts, involved in the process of selecting specialty by physicians in the country, who were not among participants (Table 6).

These people, while verifying the model, acknowledged that this model would perfectly match the existing conditions of choosing specialty at the country level, and the medical education system does not play its part well as a trustee. In fact, the health system and payment methods should change. Given that our system is an absolute capitalist system and it is the money that creates value, "the utility and prosperity in life" box is more important and more colorful, that is, people will choose specialty from this respect.

This means that, unlike the rest of the world, people here do not think about how much their interests or abilities are or how much they are effective for the society. Many do not have a choice. They participate in the exam and choose a specialty based on whether their rank fits into that specialty, how much money they will make, how easy their work and life will be. 
So if the service delivery model in the health system changes and correspondingly the payments change, the type of people's choice also changes, that is, if we need cheap health, we must shake our health system with these control knobs and control the payment system, insurances, etc., for the people to prefer specialties that we need most.

\section{The Study Limitations}

No researcher, especially in qualitative research, can act completely objective, and their ideas and thoughts may influence the study process. In order to control this issue during the course of the study, researchers tried to identify their thoughts, ideas, and beliefs about the research subject and do not involve them in the process of collecting and analyzing data by bracketing or mention them in memos.

In addition, due to the possibility of the participants' bias toward expressing favorable opinions or cautiousness in expressing their views and opinions clearly, it was tried to ensure all participants that they are free to express their opinions and no judgments will be made about them, to control this limitation.

\section{CONCLUSION}

The results of the study indicated that in order to achieve the ultimate goal of choosing a specialty, namely the expected utility, the conditions and requirements for achieving the expected utility should be provided for the educational and occupational levels, and future life.

Findings show that the existence of a rich academic and professional culture, paying attention to talents and intellectual abilities of individuals rather than prestige of the degree, and the existence of a developed welfare system in the country, as areas influencing the choice of specialty with the aim of achieving utility, can be effective to provide the individual's and high health system criteria, different specialties, and fair distribution of physicians.

Based on the data of this study, it seems that a strong welfare and a social insurance system that can provide the occupational and economic security for individuals, will reduce the impact of the financial outcomes of the specialties and move people toward their interests.

\section{ACKNOWLEDGEMENTS}

This article is part of a doctoral dissertation and approved by the Shahid Beheshti University of Medical Sciences Ethics Committee (IR.SBMU.RETECH.REC.1395.152) dated 1395.2.19=8 May 2016).

\section{REFERENCES}

1. de Souza LCL, Mendonça VR, Garcia GB, Brandão EC, Barral-Netto M. Medical specialty choice and related factors of Brazilian medical students and recent doctors. PloS one. 2015;10(7):e0133585. https://doi.org/10.1371/journal.pone.0133585

2. Ahmad $O B$, Lopez $A D$, Inoue $M$. The decline in child mortality: a reappraisal. Bulletin of the World Health Organization. 2000;78:1175-91.

3. Ossai EN, Uwakwe KA, Anyanwagu UC, Ibiok NC, Azuogu BN, Ekeke N. Specialty preferences among final year medical students in medical schools of southeast Nigeria: need for career guidance. BMC medical education. 2016;16(1):259. https://doi.org/10.1186/s12909-016-0781-3

4. Brotherton SE, Rockey PH, Etzel SI. US graduate medical education, 2003-2004. JAMA. 2004;292(9):1032-7. https://doi.org/10.1001/jama.292.9.1032

5. Ahmed SM, Majumdar MAA, Karim R, Rahman S, Rahman N. Career choices among medical students in Bangladesh. Advances in Medical Education and Practice. 2011;2:51. https://doi.org/10.2147/AMEP.S13451

6. Ahmed SM, Majumdar MAA, Karim R, Rahman S, Rahman N. Career choices in preventive and social medicine and other non-clinical specialties among medical students: Bangladesh perspective. South East Asia Journal of Public Health. 2013;1(1):64-7. https://doi.org/10.3329/seajph.v1i1.13224

7. Al-Mendalawi MD. Specialty preferences of Iraqi medical students. The clinical teacher. 2010;7(3):175-9. https://doi.org/10.1111/j.1743-498X.2010.00358.x

8. Abdulrahman $M$, Makki $M$, Shaaban $S$, Al Shamsi $M$, Venkatramana $M$, Sulaiman $N$, et al. Specialty preferences and motivating factors: A national survey on medical students from five uae medical schools. Education for Health. 2016;29(3):231. 
9. Önder E, Dag S, Önder G. Determining the Precedence Order of the Factors Influencing Doctors' Choice of Specialty in Turkey. 2014.

10. Aslam M, Ali A, Taj T, Badar N, Mirza W, Ammar A, et al. Specialty choices of medical students and house officers in Karachi, Pakistan. 2011.

11. Ali S. Statistical Report of the hundred premiere Medical residency Exam Academic year 2016-2017. Center for measurement and Medical Education. 2016-2017.

12. Sadati AK. Money Based Reform and Distorted Doctor-patient Interaction: A Critique of the Recent Health Sector Evolution Plan in Iran. Iranian journal of public health. 2017;46(4):583.

13. Simforoosh N, Ziaee SAM, Tabatabai S. Growth trends in medical specialists education in Iran; $1979-2013$. Arch Iran Med. 2014;17(11):771-775. PMID:25365619

14. Ezatabadi MR, Rashidian A, Shariati M, Foroushani AR, Sari AA. Using Conjoint Analysis to Elicit GPs' Preferences for Family Physician Contracts: A Case Study in Iran. Iranian Red Crescent Medical Journal. 2016;18(11).

15. Mosadeghrad AM. Factors influencing healthcare service quality. International journal of health policy and management. 2014;3(2):77. https://doi.org/10.15171/ijhpm.2014.65

16. Lawrence J, Poole P, Diener S. Critical factors in career decision making for women medical graduates. Medical Education. 2003;37(4):319-27. https://doi.org/10.1046/j.1365-2923.2003.01476.x

17. Saigal $P$, Takemura $Y$, Nishiue $T$, Fetters MD. Factors considered by medical students when formulating their specialty preferences in Japan: findings from a qualitative study. BMC Medical Education. 2007;7(1):31. https://doi.org/10.1186/1472-6920-7-31

18. Grove SK. The practice of nursing research: Appraisal, synthesis, and generation of evidence. Nursing Standard. 2013;27(31):30. https://doi.org/10.7748/ns2013.04.27.31.30.b1488

19. Corbin J, Strauss A. Basics of qualitative research: Techniques and procedures for developing grounded theory. Thousand Oaks. 2008.

20. Lempert LB. Asking Questions of the Data: Memo Writing in the Grounded. The Sage handbook of grounded theory. 2007:245-64.

21. Birks M, Mills J. Grounded theory: A practical guide: Sage; 2015.

22. Alligood M, Tomey A. Numing Theorists and Their Work. St. Louis: Mosby. Elsevier; 2006.

23. Schwartz RW, Simpson WG, Strodel WE, Jarecky RK, Griffen WO, Young AB. Career change: in quest of a controllable lifestyle. Journal of surgical research. 1989;47(3):189-92. https://doi.org/10.1016/00224804(89)90105-4

24. Takeda Y, Morio K, Snell L, Otaki J, Takahashi M, Kai I. Characteristic profiles among students and junior doctors with specific career preferences. BMC medical education. 2013;13(1):125. https://doi.org/10.1186/1472-6920-13125

25. DeZee KJ, Maurer D, Colt R, Shimeall W, Mallory R, Powers J, et al. Effect of financial remuneration on specialty choice of fourth-year US medical students. Academic Medicine. 2011;86(2):187-93. https://doi.org/10.1097/ACM.0b013e3182045ec9

26. Maiorova T, Stevens F, Scherpbier A, van der Zee J. The impact of clerkships on students' specialty preferences: what do undergraduates learn for their profession? Medical Education. 2008;42(6):554-62. https://doi.org/10.1111/j.1365-2923.2008.03008.x 